\title{
Identification of microRNA precursors in Bruguiera spp.
}

\begin{abstract}
MicroRNAs (miRNA) are approximately $22 \mathrm{nt}$ single stranded functional RNAs derived from long stem-loop precursors transcribed by RNA polymerase II. They regulate gene expression through post-transcriptional gene silencing and are important for the regulation of growth, development and stress responses in plants. Mature nucleotide sequences of many miRNA families are highly conserved across the plant kingdom and can be used to identify and annotate homologs and potential miRNA targets. In this study, mature miRNA sequences retrieved from the miRNA registry (miRBase) were used to identify precursor sequences of miRNA orthologs and their potential targets among Expressed Sequence Tags (ESTs) of the mangrove species Bruguiera cylindrica (L.) Blume, B. gymnorhiza (L.) Lam. and B. sexangula (Lour.) Poir. Candidate miRNA precursors, which potentially belong to the miR156/7, miR396 and miR529 families, had high sequence identity between Bruguiera cylindrica and Bruguiera gymnorhiza, and expression of RNA was confirmed in both species. A number of candidate targets for miR396 and miR529 were also identified among EST from B. gymnorhiza.
\end{abstract}

Keyword: Bruguiera cylindrica (L.) Blume; Bruguiera gymnorhiza (L.) Lam.; EST; miRNA 